\title{
Virtual Reality as Support of Cognitive Behavioral Therapy in Social Anxiety Disorder
}

\author{
Ivan Kovar \\ Department of Mathematics, Tomas Bata University, Faculty of Applied Informatics, Nad Stranemi 4511, Zlin, 760 05, Czech Republic \\ E-mail:ikovar@utb.cz
}

\begin{abstract}
The subject of this article is the use of virtual reality as part of cognitive-behavioural therapy for inhabitants of Zlin with social anxiety disorder. A high percentage of people suffer this disorder during their lives. However, not everyone is able to cope with the situation on their own, and some have to seek professional help, which often takes several months or even years. Therefore, this research presents a method that could speed up therapy and reduce the use of pharmaceuticals. The research works with a group of people who have undergone special tests to examine their social anxiety disorder and to gauge their ability to speak fluently and their reaction speed. The first half of the people than attend regular therapeutic sessions, while the second group attends therapeutic sessions that use virtual reality. This provides space for creating anxiety situations that can be worked with. Finally, all the people are then retested to determine the difference that has occurred during the therapy between the two groups, proving the effectiveness of the new method using virtual reality.
\end{abstract}

Keywords - social anxiety; phobia; effect on humans; emotions; virtual reality; HTC Vive; modern technology; another dimension; CBT; TBU; Zlin.

\section{INTRODUCTION}

This article follows up on previous research and focuses on the use of virtual reality in treating people with social anxiety disorder in the field of communication.

Social anxiety disorder (SAD) is one of the most common psychiatric disorders with a lifetime prevalence of between $7 \%$ and $13 \%$ on the European continent. [1]

The research aimed to train people in effectively coping with situations they are afraid of, systematically boosting positive thinking and weakening negative mindsets in order to enable people to enjoy a better quality of life without using medication.

The patients are often given combined treatment (pharmacotherapy together with cognitive-behavioral therapy), which can accelerate the recovery process. However, there is speculation concerning the adverse effects of pharmaceuticals, as using medication to reduce the intensity of anxiety does not necessarily result in successful cognitive changes, i.e. the person does not learn to resist anxiety completely. [2]

Therefore, the research strives to work with modern and developing technologies to accelerate the therapy process without medication.

The research was conducted from March to the end of May 2018 at the Faculty of Applied Informatics at Tomas Bata University in Zlin.

\section{MATERIAL AND METHOD}

Virtual reality may be described as a computer system that creates a computer-generated imaginary environment [3]. This research worked with the HTC Vive virtual reality system.

\section{A. Description of the Components of HTC Vive}

The HTC Vive system consists of several parts, which, when linked up, take a person into another reality. All these components are shown in Fig. 1. The main component is the headset, to be worn on the head. This is the main part that displays the $3 \mathrm{D}$ image. Connected to the headset are headphones, which create a more realistic impression of being in a different dimension. The set also includes two controllers, one for each hand, which one uses to control one's movement in the application. Each controller contains a series of buttons offering a wide variety of controls. The set also contains two Base Stations, which sense the person's position and transmit it into the virtual world. The stations therefore need to be placed so that they sense the user from each side. The set also includes cables, some for powering the controllers and others for connecting the stations to the power supply. 


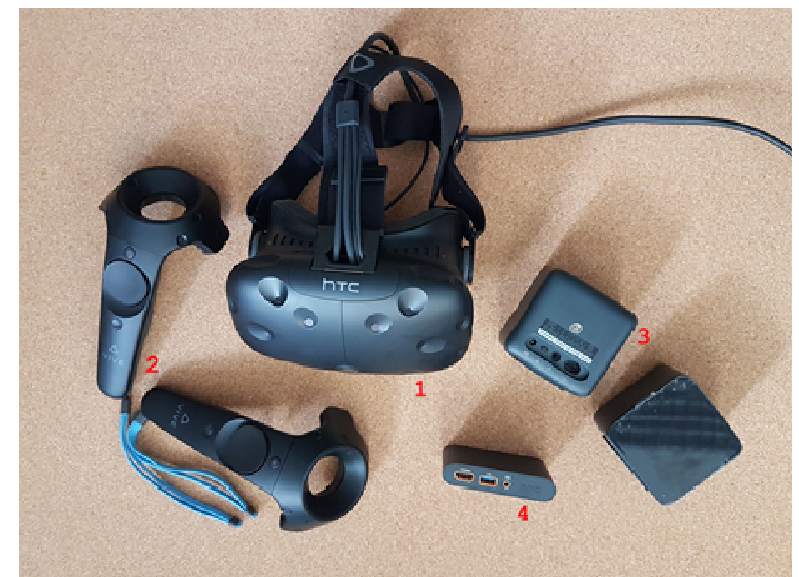

Fig. 1 Components of HTC Vive (1-Headset, 2-Controllers, 3-Base Stations, 4-Link Box)

For the HTC Vive to work properly, one needs a wellequipped computer system with a powerful graphics card. Our test set consisted of and Intel Core i7 7700 Kabylake 4.2GHz, Intel B250, RAM 16GB DDR4, NVIDIA GeForce GTX1080Ti 11GB, SSD 240GB + HDD 2000GB, Windows 10 64-bit.

\section{B. Properties and Parameters of the HTC Vive}

1) Headset: The HTC Vive has an HMD (Head Mounted Display) with a total resolution of 2160 x $1200 \mathrm{dpi}$ at a frequency of $90 \mathrm{~Hz}$. The body of the headset also contains a camera, movement sensors, a switch with an On/Off light and a swivel controller to set the distance of the optical lenses. The field of view is $110^{\circ}$ and, together with the 32 sensors, tracks movement within the entire $360^{\circ}$ range [4].

When the application has launched the user in the virtual world sees faint outlines of objects from the real world to facilitate orientation. These outlines then gradually disappear and only reappear if the user approaches the imaginary boundary that should not be crossed, as the Base Station laser beams do not reach beyond that field.

The headset, shown in Fig. 2, has soft foam material around the eyes and an adjustable strap, enabling the headset to be adjusted to suit all head types and sizes. The strap is used to attach the headset firmly on the head. The connecting cables lead behind the head, where the headphone connector also leads.

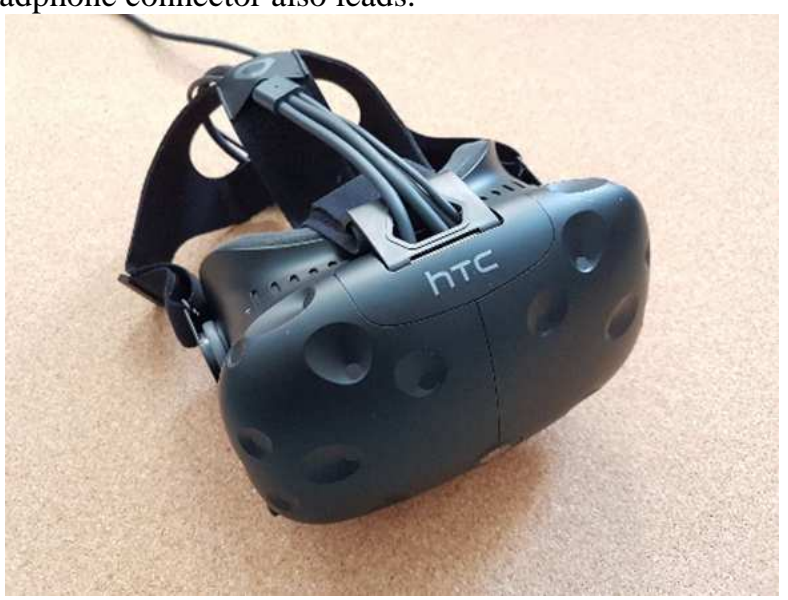

Fig. 2 Headset
2) Controllers: The set contains two controllers, one for each hand, powered by a rechargeable battery. The controller status and charge level are shown on the top of the controllers. The body of each controller contains movement sensors with Steam VR tacking. By the handle part of the controller body, there is a circular Trackpad, with a "Menu" button above it and a "System" button underneath it. On the sides, there are two "Grip" buttons and then a "Trigger" button right on the bottom of the controller. The controllers also include two-stage triggers with HD tactile feedback. The multifunctional controllers allow the user to navigate precisely, simply and naturally in applications and contain 24 sensors to precisely track their movement using the Base Stations.

3) Base Stations: The two Base Stations transmit IR (infrared) rays that alternate vertically and horizontally to fill the space. These rays are then captured by sensors (photodiodes) located in the body of the headset and controllers, and their position is then determined by these light sources. The Base Stations provide $360^{\circ}$ movement tracking. The Base Stations are mounted on the wall or furniture, or may also be fastened to high tripods. The stations must be opposite one another at the height of at least 2 meters and must be in direct line of sight. If there is an obstacle in the way, the sensors must be linked up via a synchronization cable. A status light on the stations indicates when they are linked. The beam transmitters, activity light and the display with the viewing mode are located at the front. At the back, there is the mode selection button, synchronization cable connector, a micro USB port and also the power supply. A supply powers the stations plugged into the mains socket [5].

4) Link Box: The Link Box connects the HTC Vive headset with a computer. The Link Box is powered by the power supply (included) plugged into the mains socket. On one side, there are the USB, Mini Display Port and HDMI connectors, which are for connecting up the computer. On the other side, there are the HDMI, USB and Audio connectors, to which the headset cable connects.

\section{Social Anxiety Disorder}

This is a mental disorder where the person experiences unpleasant feelings when in contact/thinking about contact with people and strives to avoid such situations. The main concern with social anxiety phobia is the fear of failure, inability to cope with situations, being ridiculed or criticized by others. The characteristic symptom of such behavior is an effort to avoid situations, which could induce anxiety, even if doing so would have negative consequences. Even though the person with the social phobia generally realizes that their anxiety symptoms are unfounded, they are often unable to suppress them in a particular situation, which leads to further feelings of inadequacy, embarrassment, and failure. Their negative thoughts are about themselves. Social anxiety phobia is not a serious mental disorder, although in the long term it can restrict the sufferer, as in today's society it is not possible to avoid communicating with people or having to perform in the presence of others [6], [7].

An estimated 3 to $13 \%$ of the world's population suffers from social anxiety phobia at some time during their lives. 
$1-3 \%$ of people suffer social anxiety disorder all their lives. This phobia of social situations generally emerges around puberty, most often somewhere between the ages of 14 to 20 [8].

Most common manifestations of social anxiety disorder:

- fear of being the center of attention;

- fear of speaking in front of authority, group, at social gatherings;

- fear of eating in front of people;

- fear of saying no or asking for something we need and are entitled to;

- fear of using public toilets;

- fear of being looked at by others;

- fear of disablement;

- fear of one is unnatural behavior;

- fear of writing in public (signing one's name at the post office, filling in forms) ;

- fear of using the telephone;

- fear of starting and continuing conversation;

- avoidance of social situations [8].

Typical physical manifestations of social anxiety disorder include trembling hands and body, blushing, sweating, heart palpitations, nausea, tightness of the throat, the sensation of having difficulty breathing, feeling faint, etc. The possible consequences of social anxiety disorder include loneliness, dependence on one's parents, learning problems, problems at work, alcohol and drug addiction, periods of depression, and, in extreme cases, attempted suicide [8].

Effective means of treating social anxiety disorder include cognitive behavioral therapy (CBT) and treatment with antidepressants (mainly if the patient also has another anxiety disorder or depression). Cognitive-behavioral procedures in the treatment of social phobia involve practicing ways of effectively coping with feared situations, systematically boosting positive thinking and weakening negative mindsets [9].

\section{Methods of Measuring Anxiety}

1) Brief Fear of Negative Evaluation Scale (BFNE): The BFNE measures anxiety associated with the perception of negative evaluation. The test contains 12 questions describing fear or concern. The individual indicates the level that best applies to them on a scale of 1 to 5, where 1 means: does not apply to me at all, and 5: extreme applies to me. Eight of the twelve questions describe fear or concern, while the remaining four describe the absence of fear or concern. The total score ranges from 12 to 60 , with a higher score indicating a higher degree of anxiety. [10]

2) Social Phobia Inventory (SPIN): The SPIN method is used to measure social anxiety/concern, fear, physiological symptoms and avoidance of social situations. The SPIN test contains 17 questions and is divided up into three categories according to the following factors: fear, avoidance and avoidance symptoms. Each of the 17 questions is evaluated on a scale of 0 to $4(0=$ not at all, $1=$ a little, $2=$ partially, 3 $=$ often, $4=$ completely). The total score ranges from 0 to 68 , with a higher score indicating a higher degree of anxiety. [11]

3) Social Interaction Anxiety Scale (SIAS): The SIAS is a simple and fast method. It consists of 20 questions, each with a 5-point scale ranging from 0 to 4 , where 0 means: does not apply to me at all, and 4: applies to me. It is intended to measure social anxiety defined as "anxiety when meeting and conversing with others." The SIAS and SPIN are used simultaneously to measure complementary aspects of social phobia. This test enables the symptoms of social anxiety to be monitored over time and may be useful in assessing social phobia or other related disorders. The SIAS score ranges from 0 to 80 , with a high score indicating a high degree of social anxiety [10].

4) Metacognition Questionnaire-30 (MCQ-30): The MCQ-30 questionnaire evaluates the individual differences in five factors that are important in the metacognitive model of mental disorders. Poor metacognition, in particular, may encourage obsessive and compulsive symptoms, pathological concerns and promote manifestations of anxiety. These 5 factors are cognitive confidence, positive beliefs about worry, cognitive self-consciousness, negative beliefs about uncontrollability and danger and the need to control thoughts. The score of each factor ranges from 6 to 24 points, and the total score ranges from 30 to 120 , with a higher score indicating a higher degree of inappropriate metacognitions [12].

5) Social Avoidance and Distress Scale (SADS): Each part of the SADS is a statement relating to a particular aspect of social anxiety. Respondents answer whether the statement is true or false for them. If they cannot give a definite answer, they are asked to choose the response that most closely reflects their feelings at the given moment. It is important to choose what first occurs to them, or what they first feel, and not spend a long time thinking about the answer. Answers to true/false questions obtain the total score. The SAD has a score ranging from 0 to 28 , with a higher score indicating a higher degree of social anxiety [13].

6) Beck Anxiety Inventory (BAI): The BAI methods uses a short list describing 21 symptoms of anxiety, such as fear of losing control. Respondents are asked to evaluate how affected they have been by each symptom during the last week, on a scale of 0 to 3 , where $0=$ not at all, $3=$ severely / I could barely stand it. The total score ranges from 0 to 63 , with a higher score indicating a great feeling of anxiety [14].

\section{RESULTS AND DISCUSSION}

The research part worked with a sample of people suffering from mild or moderate social anxiety disorder, specifically in connection with communication skills, in the Zlin region, aged $18-50$. The research focuses mainly on manifestations of communication and on improving verbal skills and the reframing of thought processes. People suffering from this disorder mostly picture the catastrophic scenarios of their actions. These thoughts make them even more stressed, affecting their communication accordingly.

One example is the fear of speaking to a stranger in the street in order to obtain information. The suffers imagine in advance that they will blush when they speak, will start to stutter and will seem incompetent, and so either do not speak to anyone at all, or what they have imagined happens due to their high-stress level. This reinforces their ideas about themselves and they will be afflicted by the same thoughts next time. The research thus works in similar situations, 
where people train their communication skills and thus strengthen positive thoughts.

\section{A. Presentation of Research}

The research was conducted amongst 10 people with a similar problem. All the people had problems communicating fluently in front of strangers, felt nervous, a tightness in the throat, nausea, or were unable to speak coherently. Basic information about the people involved in the research can be seen in Table 1 .

At the first and last - tenth session of the research all the participants underwent the same process, during which they filled in tests measuring their level of anxiety.

They then experienced two situations designed to determine their ability to respond to a given situation and Speak fluently. In the first situation, they had a simulated job interview, in which they were supposed to impress the interviewer with their abilities and skills and answer why they themselves should be given the job. During the interview each individual was asked ten questions, after which the arithmetic average of their reaction speed was calculated. In the second situation they found themselves in front of a group of 15 people, to whom they had to speak about their favourite activity. During this situation the average amount of time for which they spoke fluently was measured. Neither of these situations used virtual reality.
In Table 2 can be seen the results from the individual tests assessing the degree of anxiety, the length of time for which the respondents spoke fluently and their average reaction speed to the questions from the first session.

The people were then divided up into two groups, with half of the people continuing to attend just the normal sessions with a psychologist and the other half of the group, besides their normal sessions, also attending therapy sessions using virtual reality.

After the end of all the therapy sessions using VR all the participants again got together and filled in the same tests that they had at the beginning and underwent the same simulated situations. Finally, the results from the first and last sessions were compared.

\section{B. Background of Research Based on the Use of Virtual Reality for Therapy}

There were a total of 8 sessions with each of the five participants. Virtual reality was used to create an anxiety environment, in which the individuals practised their communication skills and their ability to cope with anxiety. During each session they each underwent the same phases.

At the start of each therapy session the individuals were told about the situation they would undergo. At the beginning they had time to think, while in later sessions they were put straight into the situation.

TABLE I

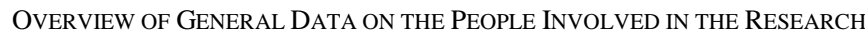

\begin{tabular}{|l|l|l|l|l|l|l|l|l|l|l|}
\hline & Person 1 & Person 2 & Person 3 & Person 4 & Person 5 & Person 6 & Person 7 & Person 8 & Person 9 & Person 10 \\
\hline Gender & woman & woman & man & woman & man & man & woman & man & man & woman \\
\hline Age & 19 & 36 & 45 & 23 & 32 & 51 & 43 & 22 & 27 \\
\hline Medication & yes & no & no & no & no & no & no & no & no & yes \\
\hline $\begin{array}{l}\text { Level of } \\
\text { education }\end{array}$ & university & $\begin{array}{l}\text { secondary } \\
\text { school }\end{array}$ & apprenticeship & $\begin{array}{l}\text { secondary } \\
\text { school }\end{array}$ & university & university & $\begin{array}{l}\text { secondary } \\
\text { school }\end{array}$ & $\begin{array}{l}\text { secondary } \\
\text { school }\end{array}$ & university & $\begin{array}{l}\text { elementary } \\
\text { school }\end{array}$ \\
\hline $\begin{array}{l}\text { Approximate } \\
\text { year in } \\
\text { which they } \\
\text { first } \\
\text { experienced } \\
\text { anxiety }\end{array}$ & 2014 & 2002 & 1990 & 2008 & 2007 & 1997 & 2001 & 2012 & 2003 & 1998 \\
\end{tabular}

TABLE II

RESUlTS OF FIRST MEASUREMENTS

\begin{tabular}{|l|l|l|l|l|l|l|l|l|l|l|}
\hline & Person 1 & Person 2 & Person 3 & Person 4 & Person 5 & Person 6 & Person 7 & Person 8 & Person 9 & Person 10 \\
\hline BFNE & 41 & 31 & 36 & 26 & 28 & 31 & 39 & 37 & 24 & 49 \\
\hline SPIN & 53 & 46 & 41 & 38 & 45 & 35 & 59 & 47 & 28 & 61 \\
\hline SIAS & 51 & 46 & 62 & 52 & 57 & 40 & 63 & 69 & 54 & 58 \\
\hline MCQ-30 & 80 & 74 & 70 & 53 & 59 & 55 & 92 & 68 & 66 & 99 \\
\hline SADS & 20 & 19 & 16 & 10 & 12 & 12 & 23 & 17 & 14 & 25 \\
\hline BAI & 44 & 38 & 41 & 26 & 31 & 24 & 48 & 37 & 29 & 53 \\
\hline $\begin{array}{l}\text { Reaction } \\
\text { speed (s) }\end{array}$ & 9 & 8.5 & 8 & 6 & 7 & 6.5 & 10 & 8 & 7.5 & 11 \\
\hline $\begin{array}{l}\text { Length of } \\
\text { fluent } \\
\text { speech (s) }\end{array}$ & 141 & 172 & 189 & 287 & 258 & 305 & 250 & 196 & 415 & 129 \\
\hline $\begin{array}{l}\text { Therapy } \\
\text { using VR }\end{array}$ & no & no & no & no & no & yes & yes & yes & yes & yes \\
\hline
\end{tabular}


After the completion of each situation, there was an opportunity to hear feedback from an expert. At the end there was a relaxation phase, designed to help the people relax and ease their stress and nerves. A simple progress chart is shown in Fig. 3.

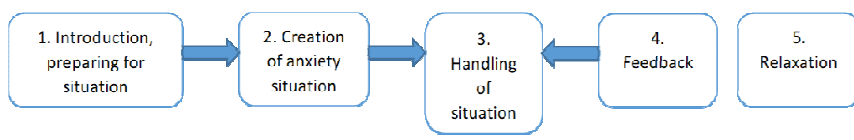

Fig. 3 Chart showing the course of therapy using virtual reality

\section{Phases of the Research}

1) Phase - Introduction to Situation: At the beginning of each session the patient was informed of the situation he or she would face. The patients had time to prepare for the situation and discuss together about how they could respond assertively and how they should behave. They were then placed into virtual reality, where they found themselves in an unpleasant situation.

2) Phase - Creation of an Anxiety Situation: The participants, viewing the world through virtual reality, gradually found themselves in a situation that could induce anxiety. A specific story unfolded before their eyes - a situation to which they had to respond correctly. The authenticity of the atmosphere was enhanced by subtle sounds in the background of the situation, although the main conversation was between the individual and the researcher. In the Fig. 4 there can be seen an individual during her course of the therapy.

The first sessions used situations that were simpler for the individuals, after which the difficulty was increased. In the final sessions, the individuals worked with situations they had not been prepared for and had to deal with them as they happened, just like in real life.

The situations most commonly used in the therapy included public speaking, a telephone call from a random institution, criticism of their appearance or a character trait, a job interview, refusal of an unsuitable job offer / unwanted product or working lunch.

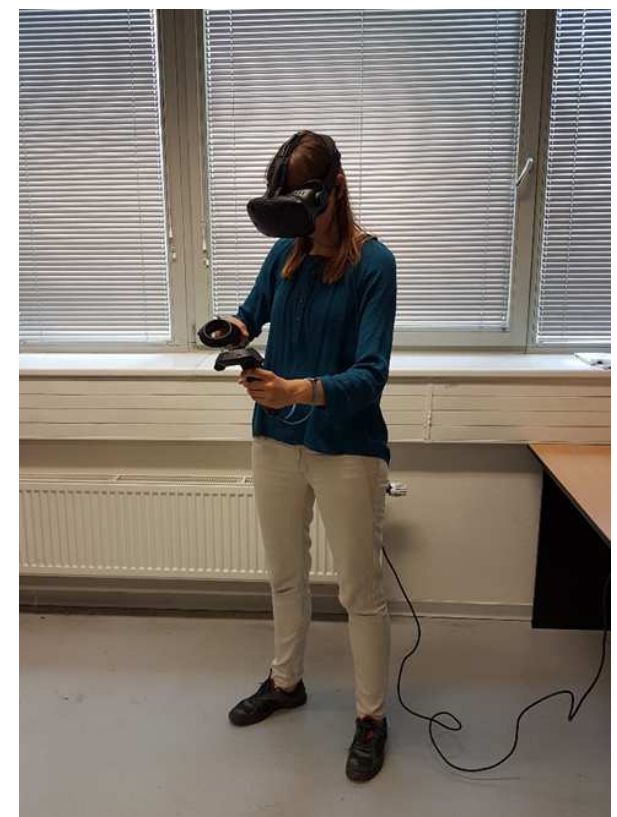

Fig. 4 Individual during the therapy
3) Phase - Work with Situations and Subsequent Consultation: The communication was monitored by an expert the entire time, who later provided feedback based on notes taken during the session. The aim was to analyze the situation and draw attention to details that needed more work, how to remain calm during a given situation, and also to highlight positive reactions and choice of language. The expert also worked with the negative automatic thoughts that occurred to the individuals during the situations and strived to reframe them together with the participants.

4) Phase - Relaxation and Winding-Down Time: In the last phase virtual reality was used to relax and wind down as can be seen in Fig. 5 and Fig. 6.

The individuals had the choice of the following applications:

- painting in 3D space;

- magic tricks and experiments;

- sports;

- walks in nature;

- insight into history;

- work on a farm, looking after animals.

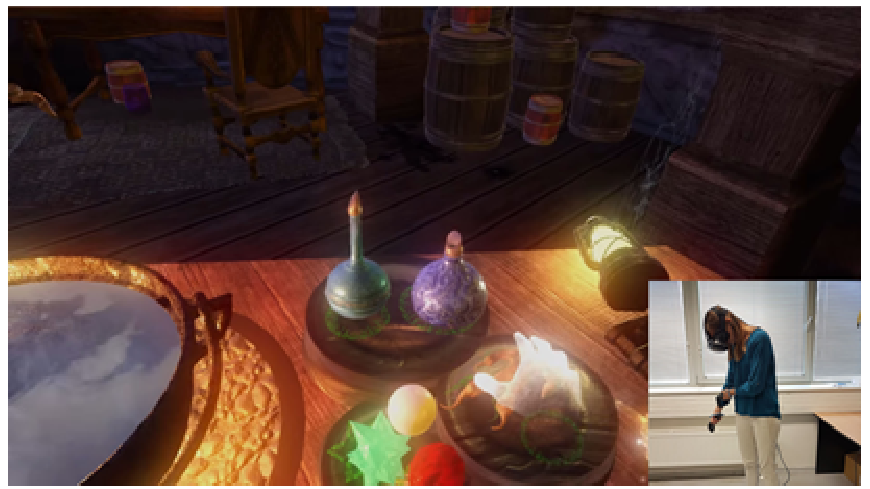

Fig. 5 Individual during the relaxation phase - magic tricks and experiments

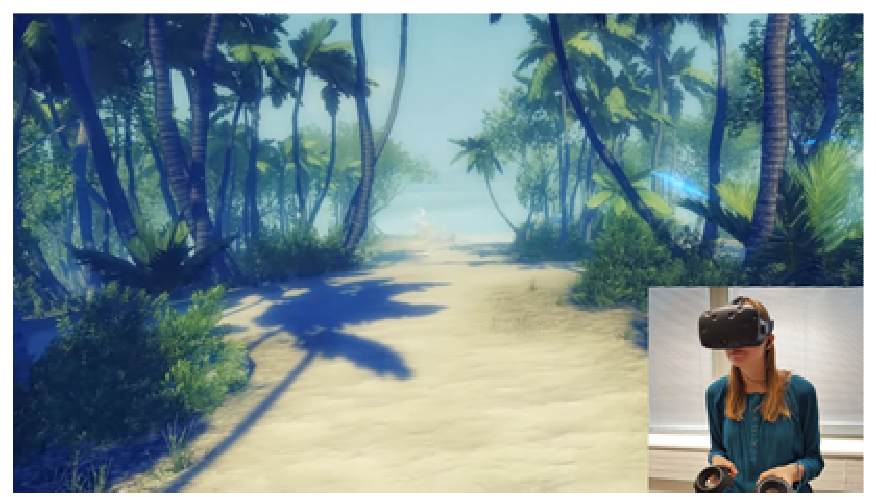

Fig. 6 Individual during the relaxation phase - walks in nature

The individual had 15-20 minutes to use virtual reality simply to relax. The researcher did not intervene in this phase unless asked to by the individual. The aim was to calm and relax the individual after the demanding process and to provide them with the chance to enjoy something they like doing and forget for a while the stress they have been under.

\section{Final Measurement}

At the tenth session (after 8 VR sessions with each of the 5 participants) all ten people were measured again. Once again they filled in the same tests and underwent the same 
two situations as they did at the start. The results from the final measurement can be seen in Table 3 .

\section{E. Summary of Research}

The difference in the measurements at the start and the end of the research is shown in Table 4. The differences in the measurements for all the research methods show that the people who underwent the treatment using VR achieved a markedly better score than those who attended just the regular psychological therapy sessions. The difference in reaction speed at the simulated job interview at the start and the end of the research are expressed as the time by which the reaction time was reduced in the simulated situations we measured. The difference in the length of fluent speech expresses how many seconds longer the person's speech was in the simulated talk. The research shows that all the participants made a certain degree of progress. However, the difference is more marked in the group that used virtual reality.

In order to provide a more explicit overview of Table, 5 shows the arithmetical averages of the differences in the measurements for the individual methods and procedures for all the people from each of the groups reviewed. The table shows that the most significant improvement was in the length of fluent speech, where the individuals who completed the therapy using VR improved by an average of 204.8 seconds. In contrast, VR did not have a too high impact on reaction speed in the simulated job interview.

TABLE III

RESULTS OF MEASUREMENT

\begin{tabular}{|c|c|c|c|c|c|c|c|c|c|c|}
\hline & Person 1 & Person 2 & Person 3 & Person 4 & Person 5 & Person 6 & Person 7 & Person 8 & Person 9 & Person 10 \\
\hline BFNE & 38 & 29 & 32 & 23 & 25 & 26 & 34 & 33 & 20 & 41 \\
\hline SPIN & 49 & 42 & 37 & 35 & 41 & 29 & 50 & 41 & 22 & 54 \\
\hline SIAS & 45 & 41 & 57 & 47 & 54 & 31 & 58 & 60 & 49 & 50 \\
\hline MCQ-30 & 74 & 70 & 64 & 48 & 50 & 45 & 79 & 55 & 58 & 82 \\
\hline SADS & 17 & 16 & 10 & 8 & 8 & 8 & 17 & 14 & 10 & 18 \\
\hline BAI & 39 & 36 & 37 & 23 & 27 & 16 & 32 & 27 & 20 & 43 \\
\hline $\begin{array}{l}\text { Reaction } \\
\text { speed (s) }\end{array}$ & 7.5 & 7 & 6 & 4.5 & 5 & 4 & 5 & 5.5 & 4.5 & 6 \\
\hline $\begin{array}{l}\text { Length of } \\
\text { fluent } \\
\text { speech (s) }\end{array}$ & 261 & 294 & 237 & 373 & 328 & 610 & 430 & 348 & 673 & 308 \\
\hline $\begin{array}{l}\text { Therapy } \\
\text { using VR }\end{array}$ & no & no & no & no & no & yes & yes & yes & yes & yes \\
\hline
\end{tabular}

TABLE IV

DIFFERENCE IN MEASUREMENTS

\begin{tabular}{|l|l|l|l|l|l|l|l|l|l|l|}
\hline & Person 1 & Person 2 & Person 3 & Person 4 & Person 5 & Person 6 & Person 7 & Person 8 & Person 9 & Person 10 \\
\hline BFNE & 3 & 2 & 4 & 3 & 3 & 5 & 5 & 4 & 4 & 8 \\
\hline SPIN & 4 & 4 & 4 & 3 & 4 & 6 & 9 & 6 & 6 & 7 \\
\hline SIAS & 6 & 5 & 5 & 5 & 3 & 9 & 5 & 9 & 5 & 8 \\
\hline MCQ-30 & 6 & 4 & 6 & 5 & 9 & 10 & 13 & 13 & 8 & 17 \\
\hline SADS & 3 & 3 & 6 & 2 & 4 & 4 & 6 & 3 & 4 & 7 \\
\hline BAI & 5 & 2 & 4 & 3 & 4 & 8 & 6 & 10 & 9 & 10 \\
\hline $\begin{array}{l}\text { Reaction } \\
\text { speed (s) }\end{array}$ & 1.5 & 1.5 & 2 & 1.5 & 2 & 2.5 & 5 & 2.5 & 3 & 5 \\
\hline $\begin{array}{l}\text { Length of } \\
\text { fluent } \\
\text { speech (s) }\end{array}$ & 120 & 122 & 48 & 86 & 70 & 305 & 180 & 152 & 258 & 179 \\
\hline $\begin{array}{l}\text { Therapy } \\
\text { using VR }\end{array}$ & no & no & no & no & no & yes & yes & yes & yes & yes \\
\hline
\end{tabular}

TABLE V

AVERAGE DiFFERENCES In MEASUREMENTS

\begin{tabular}{|l|l|l|}
\hline & $\begin{array}{l}\text { The average result } \\
\text { with normal therapy }\end{array}$ & $\begin{array}{l}\text { The average result } \\
\text { with using VR } \\
\text { therapy }\end{array}$ \\
\hline BFNE & 3 & 5.2 \\
\hline SPIN & 3.8 & 6.8 \\
\hline SIAS & 4.8 & 7.2 \\
\hline MCQ-30 & 6 & 12.2 \\
\hline SADS & 3.6 & 4.8 \\
\hline BAI & 3.6 & 8.6 \\
\hline $\begin{array}{l}\text { Reaction speed } \\
\text { (s) }\end{array}$ & 7.7 & 8.6 \\
\hline $\begin{array}{l}\text { Length of fluent } \\
\text { speech (s) }\end{array}$ & 89.2 & 204.8 \\
\hline
\end{tabular}

\section{CONCLUSION}

The primary aim of the research was to determine whether virtual reality can be used as part of cognitive-behavioral therapy for people suffering from social anxiety disorder, specifically regarding their communication skills. The research demonstrates that VR offers a means of creating model situations where people with the disorder can learn verbal skills and work with manifestations of anxiety in a more realistic environment than if they were working on those skills without using VR. Moreover, the available feedback provided the opportunity for users to realize their mistakes or weaknesses and see them from a different perspective. This then made it easier to work with the 
negative thoughts that are common to this group of people. The use of VR to subsequently relax and ease stress had a positive impact on the therapy and made it more effective.

The research resulted in the finding that virtual reality has a generally positive impact on a person's mental state. It may be assumed that it will be used much more in various areas of healthcare. It is inevitable that this modern technology will continue to be developed and refined, making it even more widely applicable in supporting mental activity.

\section{ACKNOWLEDGMENT}

This paper was prepared with the support by grant no. IGA/FAI/2018/017 from Internal Grant Agency of Tomas Bata University in Zlin.

\section{REFERENCES}

[1] KIM, Hesun Erin, Yeon-Ju HONG, Min-Kyeong KIM, Young Hoon JUNG, Sunghyon KYEONG and Jae-Jin KIM. The effectiveness of self-training using the mobile-based virtual reality program in patients with social anxiety disorder. Computers in Human Behavior. 2017, 73, 614-619. DOI: 10.1016/j.chb.2017.04.017. ISSN 07475632. Available:

http://linkinghub.elsevier.com/retrieve/pii/S0747563217302595

[2] KOSOVÁ, Jiřina. Co opravdu funguje u úzkostných poruch: $\mathrm{k}$ terapeutickým kombinacím přidáme cvičení. Psychiatrie pro praxi. Solen, 2010, 11(1), 11-14. ISSN 1803-5272.

[3] SOBOTA, B. and F. HROZEK. Virtualna realita a jej technologie. Ostrava: Datakon Znalosti, 2013. ISBN 978-80-248-3189-3.

[4] NIEHORSTER, Diederick C., Li LI and Markus LAPPE. The Accuracy and Precision of Position and Orientation Tracking in the HTC Vive Virtual Reality System for Scientific Research. IPerception. 2017,8(3), 204166951770820-. DOI: 10.1177/2041669517708205. ISSN 2041-6695. Available: http://journals.sagepub.com/doi/10.1177/2041669517708205

[5] BORREGO, Adrián, Jorge LATORRE, Mariano ALCAÑIZ and Roberto LLORENS. Comparison of Oculus Rift and HTC Vive: Feasibility for Virtual Reality-Based Exploration, Navigation, Exergaming, and Rehabilitation. Games for Health Journal. 2018, , -.
DOI: $10.1089 / \mathrm{g} 4 \mathrm{~h} .2017 .0114$. ISSN 2161-783X. Available: http://www.liebertpub.com/doi/10.1089/g4h.2017.0114

[6] DUDKOVÁ, Anna. Úzkost jako diagnóza (soubor publicistických interview). Brno, 2015. Bachelor thesis. Faculty of Social studies, Masaryk University.

[7] Nové trendy v léčbě úzkostných poruch. Postgraduální medicína [online]. Mladá fronta, 2014 [cit. 2018-05-24]. Available: https://zdravi.euro.cz/clanek/postgradualni-medicina/nove-trendy-vlecbe-uzkostnych-poruch-475776

[8] PRAŠKO, Ján, Jana VYSKOČILOVÁ and Jana PRAŠKOVÁ Sociální fobie a jeji léçba: př́ručka pro lidi se sociální fobii. Praha: Galén, 2008. ISBN 978-80-7262-580-2.

[9] Sociální fobie, sociální úzkostná porucha. Naše info zdraví [online]. Lunar Media [cit. 2018-05-24]. Available: http://www.naseinfo.cz/psychologie/socialni-fobie-socialni-uzkostnaporucha\#ixzz5Etsd45PL

[10] TAVOLI, Azadeh, Mahdiyeh MELYANI, Maryam BAKHTIARI, Gholam Hossein GHAEDI and Ali MONTAZERI. The Brief Fear of Negative Evaluation Scale (BFNE): translation and validation study of the Iranian version. BMC Psychiatry. 2009,9(1), -. DOI: 10.1186/1471-244X-9-42. ISSN 1471-244X. Available: http://bmcpsychiatry.biomedcentral.com/articles/10.1186/1471244X-9-42

[11] LETAMENDI, Andrea M., Denise A. CHAVIRA and Murray B. STEIN. Issues in the Assessment of Social Phobia: A Review. 2009, 46(1), 13-24.

[12] WELLS, Adrian and Sam CARTWRIGHT-HATTON. A short form of the metacognitions questionnaire: properties of the MCQ30. Behaviour Research and Therapy. 2004, 42(4), 385-396. DOI: 10.1016/S0005-7967(03)00147-5. ISSN 00057967. Available: http://linkinghub.elsevier.com/retrieve/pii/S0005796703001475

[13] Sobański JA, Klasa K, Rutkowski K,. Social Avoidance and Distress Scale (SAD) and Fear of Negative Evaluation Scale (FNE) reliability and the preliminary assessment of validity. Psychiatr Pol. 2013;47(4), 691-703.

[14] MUNTINGH, Anna DT, Christina M VAN DER FELTZCORNELIS, Harm WJ VAN MARWIJK, Philip SPINHOVEN, Brenda WJH PENNINX and Anton JLM VAN BALKOM. Is the beck anxiety inventory a good tool to assess the severity of anxiety? A primary care study in The Netherlands study of depression and anxiety (NESDA). BMC Family Practice. 2011, 12(1), -. DOI: 10.1186/1471-2296-12-66. ISSN 1471-2296. Available: http://bmcfampract.biomedcentral.com/articles/10.1186/1471-2296$12-66$ 